\title{
Practicing Language Therapy for Effective Simultaneous Bilingualism: Case Studies
}

\author{
Fatima Zafar Baig ${ }^{1}$, Muhammad Zammad Aslam², Tahir Yaseen ${ }^{3}$, Hafiz Shabir Ahmad ${ }^{1}$, Muhammad Murtaza $^{1} \&$ \\ Muhammad Javid Abbas ${ }^{1}$ \\ ${ }^{1}$ National College of Business Administration \& Economics, Multan, Pakistan \\ ${ }^{2}$ National University of Modern Languages, Islamabad, Pakistan \\ ${ }^{3}$ Institute of Southern Punjab, Multan, Pakistan \\ Correspondence: Muhammad Zammad Aslam, National University of Modern Languages, Islamabad, Pakistan. \\ E-mail: zammad.aslam@gmail.com
}

Received: October 1, 2019 Accepted: November 28, 2019 Online Published: December 28, 2019

doi:10.5539/ijel.v10n1p230 URL: https://doi.org/10.5539/ijel.v10n1p230

\begin{abstract}
Bilingualism and multilingualism are not a typical phenomenon in this present world, rather, it is a norm in the world's societies these days. People may happen to be bilingual either by acquiring two languages parallelly in their life since childhood or learn with the passage of time as sequential and simultaneous bilinguals. The current study aims to find out the role of language therapists, in terms of supporting parents and teachers, to benefit maximum out of this dual-language ability of their young children, for this case studies were conducted to investigate the question and it was concluded that balanced use of both languages help a child to perform well with proper guidance of language professionals to the parents and teachers. Furthermore, parents always seem trying their child become bilingual because they consider it a positive thing for the better future of their child. This age is the age of advanced technology and science in which new skills are required and demanded. Nowadays, in the whole world, different languages are being used in this technological progress, especially, the developed countries dominate in this field (technology) due to their advanced knowledge in different fields. Hence, the developed countries use their own language(s) in technology and inventions that make it essential to learn more languages. These case studies also depict how much it is advantageous or disadvantageous being bilingual or multilingual.
\end{abstract}

Keywords: bilingualism, language development, simultaneous bilingualism, language therapist

\section{Introduction}

Learning two languages does not mean that a child has a strong grip or hold on any language which he or she learns. Bilingual kids build up dual language ability just as other children do in their specific duration. For instance, children are uncovered to manifold languages in their childhood as concurrent bilinguals gain language at equal speed as children exposed to a solo language. Likewise, children, all over the world, get hold of more than one language without being failed of developing language or speech delays. In addition to this, there is no precise proof of the dot that children with definite developmental disabilities or definite language mutilation cannot attain more than one language (Paradise et al., 2003). A child with speech and language complicatedness will get a benefit by being encircled by many family members and relatives who are in no doubt in their use of language, so that, he or she keeps upbeat and twofold language role models. It is reported that around $66 \%$ of the world's children are raised bilingual (Marian \& Shook, 2012).

As this fact that language would be said a system and this system consists of words that have sense and convey meanings. For instance, Lee (1992) states a "language is an instrument for the phenomena of human experience to conceptual categories" (as cited in Aazam et al., 2019, p. 192). Moreover, language is considered a system of grammar and rules which are used for communication. Hence, the language further plays its specific role when it works as a system used for the development of culture regarding knowledge, and personal and social identity creation in a society or speech community (Skutnabb-kangas \& McCarty, 2006). In the same way, there is sudden and rapid or quick movement from native and national matters of the 20th century to a direction which is the direction globalized and internationalized in the 21 st century, created the interconnectedness in the world of today 
(De Mejia, 2002). The merits of being brought up bilingual incorporate cognitive pros, for instance, better common way of thinking, societal understanding, cognitive suppleness, enlarges meta linguistic consciousness (the ability to think and talk about language), and improves rate of language incorporation and withholding. Language is a fundamental part of cultural individuality (Scarino \& Liddicoat, 2009, p. 15). One of the supreme advantages of being raised bilingual is that a teenager obtains enormous disclosure to two or more added cultures. Knowledge of a family's local language or L1 helps to transmit the family's enriching legacy and customs to prospect generations. It is noteworthy for caregivers to carry out the language they are most comfortable with when interacting with children, as it boosts to accommodate and promote collective and language development. Being bilingual is an ability, and in order to make use of it better, children require a great deal of practice in the dwelling, which caregivers can help to grant. Caregivers ought to verbalize the language they are most convenient with so that they might bestow children a fine language representation. They would promote reading and other types of entertainment (DVDs, music) in both targeted languages. It is not atypical for children to defy speaking in their home language as soon as they turn into expert in English. Nearly 10\% of children can be, estimated, in troubles with language growth. This is similar to monolingual or bilingual children. The causes of difficulties with language growth are diverse and intricate. But bilingualism is not one of them. Bilingualism is not a load for children, and it is not perplexing. All the facts, we have to date, points out that bilingualism brings us at finest cognitive merits, at worst no disparity to monolinguals on a broad array of IQ associated tests (see Bloom et al., 2017 for details).

On language tests, representative bilingual children carry out their work within the usual range in, at least, one of their languages. Undoubtedly, children may perhaps not yet have had enough revelation to English to be at the level anticipated for their age. In time and with contribution which ropes language maturity, this would correct itself if there are no primary difficulties with language progress. FKA proposes awareness about what to look ahead to from children who get hold of English as a subsequent language and how to prop them up (reference). Being a second language apprentice is unlike from having language turmoil. For the period of the past hundred years, the researchers' approach towards the fact of bilingualism has gone through some basic alteration. At the commencement of the twentieth century, researchers and scientists believed that the usage of an alien or a second language with an immature child was an unpardonable offense (Cummins, 2000). The condition was so dismal that those scientists and researchers supposed that bringing in a second or an overseas language to a little adolescent was one of the foremost causes for cerebral retardation in youngsters. Conversely, with the vast development in examining techniques and enlarged awareness of the theme, educators, language professionals and researchers now get inclined to comply with that bilingualism, is a grand skill to both the child and the world (Byers-Heinlein \& Lew-Williams, 2013). The bilingual phenomenon has turned into so much admired to the extent that even monolingual parents who do not reside in a bilingual society, are so much eager on putting their children into kindergarten and school engagement programs to cherish the children's linguistic competence and to give them a head's start in life (ibid).

Talking particularly about the past three decades, there has been conducted, fairly, a bunch of studies in bilingualism as a psycholinguistic case for young children. The cause, on the background of this rising trend, is the contentious type of bilingualism particularly during the early phase of childhood (see Brice \& Brice, 2009 for details). This controversy is caused by a lot of significant issues. First, how premeditated or unintentional is the bilingual movement? (see Cortina, Makar, \& Mount-Cors, 2015 for details), Second, are the two languages acquired 'or even learned at the same time' or one after the other? Third, what is the consequence of bilingualism on other cognitive activities? For example, does the gaining 'or even acquisition' of a second language grow other than one's native tongue which accommodates or hampers other cognitive abilities in children? (see Valian, 2015 for details), Fourth, what is the consequence of the background or the situation in which the bilingual activity occurs? Moreover, how far does it impinge on the extent of bilingualism in immature age? (see Byers-Heinlein \& Lew-Williams, 2013 for details). Most of the study carried out on bilingualism in adolescent age was much more concerned with the outcome of this observable fact on the linguistic and the cognitive capabilities of young children, and with the discrepancies amid the bilingual children and their monolingual peers in terms of linguistic and cognitive improvement. For example, Ben-Zeev (1977) probed into the dissimilarity between monolingual and bilingual kids on a sign substitution undertaking. The subjects of the study were 96 children whose ages ranged from 5 to 8 years, and all of them belonged to mediocre families. The research subjects were commanded to alternate one meaningful word with another in a set sentence. The outcomes of the research demonstrated that bilingual children had more comprehension of the capricious linking a definite word and its referent. Monolingual children, on the other hand, had issue in distinguishing the word from its referent. The investigator interpreted her upshots more pinpointing of the conception that bilingual children have a more investigative outlook to language than their monolingual peers. Lastly, the researcher comes to the point that bilingual children's gaining 'or 
learning' of two languages that have two diverse linguistic structures made them improved processors of oral linguistic performance than monolingual children.

There are some fallacies related to the linguistic phenomenon of bilingualism. These misbelieve and false impressions are the roots on which challengers of bilingual teaching rely on their umbrage of any shape of taking up of bilingual learning. The declaration that bilingualism puzzles children and lower their aptitude, as declared by Kandolf (1995) on the Bilingual Families interlink, is backed by research studies carried out in the United States on the distinctions amid bilingual and monolingual kids in their language presentation. In these investigations, monolingual children performed better as compared to their monolingual peers. Conversely, the issue with these investigative studies is that for the most part of them were badly structured, and the bilingual children incorporated in the studies were up to date immigrants residing under nerve-racking situations in a shape of bilingualism that is taken subtractive rather than additive, and hence it was usual for these suffering bilingual children to get lesser in language competency tests than their recognized unperturbed monolingual corresponding ones. Some researchers and educators chiefly depended on outcomes from the badly-structured above mentioned researches to go for the conclusion that bilingualism is a reason of complications for children and is a prime aspect that causes lowering down their genius (Nelson, n.d.). Conversely, it is a celebrated reality in study that conclusions and generality cannot be made on the foundation of defective study patterns.

The assertion here is that bilingualism is liable for delaying the linguistic improvement of bilingual children. Such a statement is founded on the concept that bilingual children's common senses have a more dealing out load as compared to their monolingual peers owing to the belief that in bilingual kids, the doling out mechanism is dealing with two languages concurrently while in monolingual children that structure is conducting with mainly one language (see Fuller, 2008 for details). As a denial of this declaration, investigative studies on bilingualism authenticate that in case bilingual children have a regularly-rich experience to both languages, they can undeniably arrive at the same linguistic progress as their monolingual peers. So, the main constituent in the matter of language improvement is not the number of languages 'whether one or two languages', but it is the concern of language revelation; that is, it is the extent and the excellence of language contact, and not how many languages, that settle on the phase of linguistic growth a definite monolingual or bilingual child will attain. Since in some cases, bilingual children have a lesser amount of admittance and experience to each language, they by no means turn out to be as capable in either language as their monolingual counterparts (see Potgieter, 2014 for details). This argument is opposed by a number of investigators who validate that bilingual children can certainly arrive at the same aptitude, grammatically, phonologically and lexically, as their monolingual peers (Byers-Heinlein \& Lew-Williams, 2013). Hence we should not be misled by the broad supposition that monolinguals' lexicon in the local language is much more varied than that of bilinguals; this condition is a temporary one that is caused by the fact that bilinguals are in the process of constructing two various lexical systems of two languages, and that most in all probability their cumulative lexicon of both L1 and L2 is even more than monolinguals' L1 lexicon (see Haman et al., 2017 for details).

Another faulty belief related to bilingualism is that it causes the bilingual child to build up a sense of split personalities; that is, the child feels that he or she has two different personalities. Each personality relates to each language. Some people go to the extreme by claiming that this sense seriously affects the child's loyalty to the native language and culture. This claim is simply refuted by stressing the idea that language and culture are strongly related and that mounting two different personalities in bilingualism is normal because every language has a set of cultural norms and standards, and thus it is normal for different language users to assume different roles when they are using different languages (reference). However, this idea of role assumptions does not in any way mean that the bilingual child has two diverse personalities and that he or she should be locked in a mental house. This phenomenon should be understood with ease and relaxation; that is, it is a normal behavior that only means that the bilingual child has more cultural knowledge and flexibility than his or her monolingual peer (Goundar \& Kaur, 2016).

The final misapprehension regarding bilingualism is that real bilinguals never mix the two languages, and when they do, it only means that the children are in total chaos and confusion. This is totally untrue. This linguistic phenomenon is called: code-switching. As researchers in applied linguistics signify, code-switching is a conscious linguistic device that is adopted by language users to serve several purposes such as changing the subject, accommodating a new party in the conversation, maintaining certain social roles. In fact, it has been shown that the use of two languages in one sentence by bilinguals reveals a great deal of linguistic skill (Romaine, 1995). Therefore, we cannot say that code-switching is a sign of linguistic confusion. Rather, it is a planned linguistic behavior that serves a few functions. Children develop at very different rates, the more so the younger they are. Therefore, the range of what is considered typical development is very big. Nevertheless, it is important to know at 
what point extra care and possibly steps need to be taken in order to help a child whose language enlargement is lagging. With respect to children who are speaking more than one language, many people find it particularly difficult to decide whether there are reasons for concern when a child appears to speak less English than other children. The purpose of this article is to help professionals in this verdict procedure and to take some helpful actions. This way it will be certain that parents and teachers should take dual abilities of their children as a positive scenario and language therapists will be able to help and assist children with any language impairment accordingly.

\section{Literature Review}

This chapter aims to cover theories and relevant concepts to bilingualism supported by well-famed theorists and researchers who have specialized on second language acquisition and the education-related to bilingualism. In this case, it can be observed that the mother tongue plays a pivotal role in learning languages. It may be possible that a learner has more than one mother tongue, (bilingualism/multilingualism) i.e., in Pakistan or India, an inhabitant or native person may have the chance to learn Punjabi, Saraiki, Urdu or Hindi, additionally his/her mother tongue, respectively. However, there can be minority mother tongues which may be known as heritage languages and this name is given when there may be a possibility when a child or children do not know, understand or speak minority mother tongue language (Skuttnab-Kangs \& McCarty, 2008, p. 7).

Moreover, when bilingualism is practiced individually in a small group, it can affect the behavior and attitudes of the society and this practice can be observed within the groups which are immigrants using their mother tongue which is a minority language in the community. That's why; individual bilingualism can develop in a society. Another difference can be noted between bilingualism and diglossia; in diglossia two languages are referred to which are used for different purposes. In the first purpose, it is used in matters which are officials, i.e., political and the second for situations which are formal that can also be known as interpersonal communication (De Mejia, 2002). Nonetheless, it is not easy to define bilingualism incomplete terms or fully well because there are a lot of different angles that can be responsible to affect the type and level of bilingualism as well. The age in which someone initiates to learn a second language creates a distinction that can be named as simultaneous and sequential bilingualism. The process in which a child begins learning two languages from birth side by side is called simultaneous bilingualism. Many researchers indicate as De Houwer (2009) and Genesee (2003) that a child possesses native ability and biological capacity to know the difference among languages and has the efficiency to learn or acquire them regarding input and output purposes (Baker, 2001).

In simultaneous bilingualism "one-parent-one" strategy comes under usage in which one parent speaks only one language to the child and the other parent speaks the other language to the child. It is commonly observed that one of the two learned languages purely dominate the other learned languages and all this happens in the society where a child lives and is led by the environment in which he spends his time (ibid).

The question either bilingualism is an advantage or disadvantage has always been under great debate all around the world. Researchers from various regions of the world have conducted many researches in this regard. From the 1920's till 1960's the tendency was to see monolingual children quite ahead of bilingual children on IQ tests. In the twenty-first century, all the countries including Pakistan cannot afford to exist in isolation without having been exaggerated by the global modifications and one of these changes is the fact that today half of the world is bilingual or multilingual. Moreover, there is no doubt about it that in a world of global interdependence and mass communication acquiring more than one Language abilities is a key factor for economic, social and educational accomplishment. Although research does not favor bilingualism on a closer look, we will see that many errors that we see in the field of research in bilingualism are because of the mistaken overview since our researchers' view of the world settle on the choice of material and the interpretation of findings. Cazden and Snow (1990) take bilingualism as a "simple label for a complex phenomenon". Research in bilingualism does not relate to only one discipline rather we have to cross the boundaries of disciplines and take a universal vision of bilingualism, and this portrays bilingualism a complex phenomenon as languages are used as medium of instruction and interaction in majority of the human communication scenarios. In Canada, $11.9 \%$ of the population speaks a language other than English or French at home. In Toronto, 31\% of the population speaks a language other than English or French at home. In the United States, 21\% of school-age children (between ages 5-17) speak a language other than English at home. This number is estimated to enhance in the coming years. Worldwide it is projected that there are more second-language speakers of English than native speakers. There are many bilingual children as there are monolingual children

\subsection{Developing Bilingualism}

Language development is a complex and vibrant process predisposed by the child's age language disclosure and 
social interaction. A bilingual child generally follows one of two language acquisition patterns: Simultaneous bilingualism, in which the child learns two languages at the same time before the age of three years, and sequential bilingualism, in which the child acquires a second language by the age of three after having acquired the primary language. Preschoolers may differ qualitatively from school-age children in their ability to develop a language. For older children and adults acquiring a second language is a conscious matter rather than a subconscious process, more appropriately termed language learning rather than language acquisition.

Fierro-Cobas and Chan (2001) suggested that the number of children in the United States who are exposed to two languages is growing. Pediatricians need to know how to screen for normal language development in these children, what guidance to offer parents about bilingual child-rearing, and how to answer widespread questions raised by families and teachers. Screening for language development in a child exposed to two or more languages can be demanding. Questions that commonly tackle primary care providers include delay in language development, language disorders and collision of bilingualism on language learning.

Lowry (2015), a certified speech-language Pathologist and Hanen staff member, stated various benefits of bilingualism in children. Such as, Bilingual children are better able to focus their attention on relevant information and ignore distractions; bilingual individuals have been shown to be more creative and better at scheduling and solving complex problems than monolinguals, the effects of aging on the brain are diminished among bilingual adults. In one study, the onset of dementia was deferred by 4 years in bilinguals compared to monolinguals with dementia. Bilingual individuals have greater access to people and resources. In Canada, employment rates are higher for French/English bilinguals than monolingual. Canadians who speak both official languages have a median income nearly 10\% higher than that of those who speak English only. And $40 \%$ higher than that of those who speak French only. The cognitive advantages of bilingualism seem to be related to an individual's proficiency in his languages. This means that a person would get benefit more from his bilingualism (cognitively) if he is more competent in his language.

Sampath (2005) conducted a research to find out the effects of bilingualism on intelligence and discovered that levels of second language proficiency and verbal intelligence are mutually dependent. When children have a higher level of language proficiency, they perform better on verbal intelligence. Levels of second language proficiency and range of data passed by bilingual children, the ability to solve arithmetic problems and vocabulary, are interdependent. The scale of proficiency in the second language does not affect the understanding of social justice and verbal concept formation. With reference to components of verbal intelligence, there are no sex-based differences between the linguistic groups on information, comprehension of social judgment, problem-solving abilities in arithmetic and verbal concepts formation but there is a difference in vocabulary.

Callan (2008) examined the effects of bilingualism on language development of young children and overall, simultaneous bilinguals are not at a disadvantage for their language development as compared to their peer monolinguals. Unlike simultaneous bilinguals, sequential bilingual children may take some time to learn similar skills as compared to their monolingual counterparts. Overall simultaneous or sequential bilingual children's dual language skills should be optimistic and taken positively.

Many other studies have clearly suggested that bilinguals have an advantage over monolinguals in executive control. Evidence for this claim has been obtained in studies from children (Bialystok \& Martin, 2004), young adults (Costa, Hernandez, \& Sabastain-Galles, 2008), and older adults (Gold, Kim, Johnson, Kryscio, \& Smith, 2013) using tasks presenting smaller interference effects in bilinguals than in monolinguals, including Simon (Bialystok, Craik, Klein, \& Viswanathan, 2004). As Chomsky states: "Even in the United States, the idea that people speak one language is not true. Everyone grows up hearing many different languages. Sometimes they are called "dialects or stylistic variants or whatever" but they are different languages. It is just that they are so close to each other that we do not bother calling them different languages (Chomsky, in Mukherji et al., 2000, p. 19). Flynn, Foley and Vinnitskaya (2005) advocates that language learning occurs mostly untutored and in natural settings throughout the lifespan of any individual. The research found that simultaneous and sequential bilinguals are at advantage and should be appreciated. Consequently, it can be understood that bilingualism and its effects are positive, and parents, teachers and language therapists should understand and treat such children with dual abilities of language development accordingly.

\subsection{Research Questions}

The aim of the research is to explore the challenges parents face in raising a bilingual child and support a language therapist may able to provide with the help of a case study of bilingual family. In addition, the present research would also investigate the reasons why the parents often attempt to raise their children bilingual. To find out these 
prior mentioned explorations, the research would try to answer the question as follows:

1) Does bilingualism leave effects specifically on the kids?

2) Do the parents keep specific general concerns when they decide to raise them which later to be resolved through language therapist?

3) According to parents, do the advantages of bilingualism overweigh disadvantages?

\subsection{Data Description}

The data for the present research paper are collected from Pakistani family residing in Germany, and 5 Pakistani families as well, the data are collected through semi-structured and direct interviews. One of the interviewees from the chosen family is the mother of the child whose first language is Urdu, and her second language is English with good grip over German too, hence, she speaks both languages specifically at home. She has a child who also speaks both languages as a bilingual speaker. Moreover, the father of the child is also a bilingual speaker of German and English language, yet, his German language skills better than the English language due to his professional environment. Their baby girl is 4 years old and attends kindergarten since her 3 rd year of age. This episodic study covers two phases of observation, first the early 3rd year of child's age and second last half till the age of 4 on a child residing in Germany while in single-phase Pakistani participants have been brought under research. In the first study both the parents were interviewed first about the impact of bilingualism and the child was observed and interviewed twice. And in Pakistan, parents and their kids were observed through direct conversation with them in order to know the facts of learning languages.

In the same way, the data is collected from the five Pakistani families as participants having the native, local and national language(s), i.e., Punjabi, Saraiki, and Urdu. Because the researchers are Pakistanis, therefore, they have tried to get more data and hold a research maximum on the local level in Pakistan to get more and more facts in research.

\section{Methods of Analysis}

Six families having different languages were selected for analysis regarding bilingualism aspect.

At the first stage, the parents of the child living in Germany were interviewed via video calls, and purposely the needed part of interviews was chosen for analysis. Moreover, the other five families were local (Pakistani) families, so, they were accessed and interviewed physically. Later, the selected data were transcribed and translated into the English language for the analyses. Moreover, it is also noted that the background of the first participants' native language and county or society was distinctive from the living country or society. Therefore, Takala (2016) argues that these types of case studies could be studied through various methods, for instance, field studies, observations or interviews, etc. (see Hamel, Dufour, \& Fortin, 1993 for more details). He further argues that the social attributes or features are often dealt with through the case studies into a sociological perspective (see Hamel et al., 1993, for more details). Hence, bilingualism or multilingualism could be considered a feature of social life as it studies language in the perspective of sociolinguistics in general. So, the practical implications of bilingualism or multilingualism would be achieved through the analyses of the present research. Moreover, in the second phase, language development was observed into five languages, German, English, Urdu, Punjabi and Saraiki. The differences in the language's development were also noted which leads to the intelligent code-switching phenomenon.

\subsection{Questionnaire for Interviews}

The interviews were semi-structured which refers to the objective of asking a few pre-decided open questions, eventually, few follow-up questions were also raised whenever needed. The current interviewing method was adopted because it assisted well to receive the information and data which were purposely needed. Hence, these questions were chosen because they were specifically designed to encourage the interviewees to give long and natural responses and, in this way, more information about the topic can be gathered (See Appendix I for questions for interviews).

\subsection{Research Design}

Six families and 7 children with their parents and grandparents participated in the present research. Each of six researchers of the present research selected a separate family to collect the data (according to the names mentioned above). In the discussion, the arrangement of all discussions is set up according to the researchers' names mentioned above i.e., six researchers study six families respectively as 'the first', second, third, fourth, fifth and the sixth family'. 


\section{Discussion}

The families in the present case study have very different situations. The present study focuses on five languages, German, English, and Urdu, Punjabi and Saraiki. In the first present case study, the first family that is under observation has different background regarding their language phenomenon. Living in Germany, German is the native language in most parts of Germany having a large number of speakers, yet, English is considered a second language having fewer speakers. That makes it more challenging for the children to acquire the other minority language. Within the home, the dominant language of mother is English with her first language (Urdu) interference and since her husband speaks German more there is the fusion of German vocabulary too. On the other hand, the father of the child speaks German because of professional and social reasons with the interference of English and Urdu with his wife. The child, however, is born simultaneous bilingual and with the passage of time exposed to third language but in rare situations. It was found that the child was unable to perform in the kindergarten class initially because of some communicative problems and her school language counselor arranged a meeting with the parents where a proper session was planned, and it was concluded that there would be a balanced use of both English and German languages with the child in normal routine. This guideline was followed by the parents from the child's 3rd year till now.

The second family resides in Pakistan and the researcher observes their languages whether they have competence in their language(s) or not. This is a Punjabi speaking family that intends to teach their children Urdu and English as well. At home, the mother speaks Urdu with her kid of 2.5 years old who responds to her very well but the kid's grandfather speaks Punjabi to him and the child is learning both languages at the same time. The father of the child intends to teach him the English language as well but yet he speaks Urdu using the code-switching technique. Of and on, father merges the Punjabi words while having a discourse with family members. At the same time, the child acquires the Punjabi language as well but he can't speak it well because he spends most of the time with her mother, that's why he is being competent and getting fluency in Urdu. Although, he speaks Punjabi but not fluently as Urdu.

The third family that becomes under observation belongs to a different culture having Saraiki and Punjabi languages as mother tongues. Their 4-year kid has two different mother tongues due to his parents' different languages. Father speaks Saraiki language while mother is Punjabi speaking. The kid has started going to school where education medium for all the students, is Urdu and English as well.

The child is kept observation by the researcher and it is noted that the child speaks Saraiki fluently and with ease because his environment is utterly Saraiki where he remains in contact with the Saraiki people who leave a deep impression on his personality and language. Although, he spends much time with his mother, yet his personality and culture seem impressed by the Saraiki environment. He can also speak Punjabi but not with the accent and style as his mother does. The child can speak at least three languages such as Urdu, Saraiki, and Punjabi as well but he seems more efficient, contented, satisfied, ease, comfortable and fluent just in Saraiki that shows that that child is bilingual and multilingual at the same time. Moreover, he looks better than the other ones in his proficiency in communication, perception, and transmission of ideas. That's why the idea of being bilingualism or multilingualism seems attractive in the world of today.

The fourth family that is also bilingual becomes the focus of the researchers and they find the same results but in a different angle when they start observing the family members including their kids.

Each of the parents has a different language that keeps the researcher interested in his work to find out his desired goals. Father is Urdu speaking while mother is from Punjabi background and they communicate with each other in their own possessed languages to have and maintain powerful communication keeping in view their background and culture power and status. But they compromise to speak Urdu when they talk or communicate with their 5-year kid who goes to an English medium school where she is not allowed to communicate in any local language but English. She seems to have a strong grip over Urdu because at home she spends most of her time with her parents who communicate with her in Urdu and support her in English as well. However, she understands and can speak Punjabi a little bit, without proper expertise, due to her parents' mutual conversation being an indirect participant in their conversation.

The next fifth family under research is too bilingual having the same background but different languages. All the members of the family Saraiki speakers except the mother who is Urdu speaking and tries personally to get her children avoid and away from their paternal language, Saraiki, that she never likes for her children to adopt it. However, she succeeds in her attempt a little bit, not fully well because the environment is wholly Saraikian and affects her struggles of keeping her kids away from its aftermaths. They have 2 kids, $5 \& 7$ years old respectively who go to a local government school where learning medium is Urdu. Both the kids speak the Saraiki with full 
structure and function but they can't speak Urdu with full skills and efficiency as they find it difficult to express their ideas or communicate with someone.

The sixth researcher is interested in the family that is multilingual possessing three languages at a time. The grandparents are Saraiki speaking, father is Urdu speaking while mother is Punjabi speaking. Their kids who are of $7 \& 8$-year-old speak Urdu and Punjabi skillfully due to specific supporting culture. These kids understand Saraiki, perceive it utterly and use it just for fun not for communication because they can't understand its full structure and vocabulary used on different occasions and situations. They can understand English as well because it is their learning medium at school but they are not yet able to communicate in it explicitly. Hence, it can be said that being bilingual or multilingual seems advantageous for the learners to get more and more knowledge in different fields in collaboration with different public figures and this trend shows more attraction for other learners.

The background literature, interviews and observations support the answers of the three questions positively. Interviews and background literature, answers to all three of the research questions could be found properly. For instance, 'Does bilingualism leave effects specifically on the kids?' was the first question. The interviews suggest that the children participants get influenced by bilingualism (multilingualism), for instance, in the first observation, the child learns two languages (German and English) at the same time. In the second, the child learns Urdu, Punjabi and English a little bit and so on.

The different attitudes of the families learning two languages as bilinguals are the effective factors for the child to take part in bilingualism. External as well as internal factors play a pivotal role in enhancing the efficiency of a learner of different languages. But at the same time, it is found that some learners feel difficulty to learn more than one language and it also has been observed that the same learner never wills to learn other languages than his or her mother tongue.

Most of the language experts think that the child must deal or speak with the two distinctive setups of the bilingualism. For instance, the child of the first family under observation now resides in Germany, faces difficulties to learn English as it is spoken by fewer people as a second language. Another contributing factor is the language (Urdu) spoken by the grandparents every day for 2-3 hours with the child. Now within 3 years of her age, she was exposed to two basic languages and third language for certain time and situation. When she was observed closely by the therapists and kindergarten teachers it was stated that initially, she was code-switching most frequently without understanding the situation and surroundings she was in.

The parents and teachers suggested having a visit to the therapist and according to the prescribed changes of language, parents were asked to speak two languages with the child. The mother of the child was asked to speak English with the child and the father of the child was asked to speak German with the child. This practice continued for one year and results were enormous. Now the child has a great grip over both languages, English and German. Additionally, she knew much how to code-switch. It was observed during her natural conversation of everyday life that talking in the same situation whenever any question was asked by her father she used to answer in German and similarly she replied to her mother's question in English.

Hence, in the case of Pakistani families, they all consider bilingual phenomenon as positive and supportive for their children of the contemporary age. Although, all participant children spend approximately equal time with their parents and grandparents, yet, they don't consider any L1 (Urdu) or second language (L2) as an alien language; for instance, the Urdu language is learned/acquired from the Kindergarten level of education and from the family as well. Furthermore, families and society of the area of the present research's population mostly communicate in the Urdu language (i.e. lingua franca) with each other than their mother tongue(s) (i.e., Punjabi, Saraiki or Rangri (dialect of Urdu).So, most of the people as like participants' families consider the Urdu language advantageous or sophisticated or the national language. Hence, most of the teachers also would not also mind if the students code-switch the Urdu language with their mother tongue. Additionally, the grandparents of the children often do code-switching practice with their grandchildren between the Urdu language and mother tongue(s) (i.e., Punjabi, Saraiki or Rangri (dialect of Urdu). As a developing country, the concept of language therapists is also not found in the arguments of parents and teachers of the society, so, the researchers who study the cases of Pakistani families couldn't inquire about language-specific therapists' phenomenon. Hence, the researchers feel that the parents and teachers informally work as language therapists for their children.

The second phase of research is based on all participants and it could be answered through interviews and background literature. For instance, most of the bilingual parents raise their children bilingual naturally or unconsciously. The reason behind this could seem through the already existing setup of bilingualism in the family and society (in the case of Pakistan). For instance, the families in the present research, or the parents speak different native languages in many other families in their surroundings. Moreover, the native language(s) of the 
living country (in the case of Germany) or society (in cases of Pakistan) in which they live could be distinctive from the native country or society of the parents from which they came. For instance, the native language of 'the second family' is found distinctive from the native language of the research population area. Instead, the monolingual parents keeping the same native languages would also want to raise their children bilingual (Baker, 2000 , p. 14). For instance, in many societies the language of the school children is distinctive from the language of the home, so, the parents want them to learn the language of school as a second language consciously. The factor that can contribute and assist parents is the support of language therapists and experts who can enhance the benefits of this ability.

Hence, the answer to the third research question (see the research questions) was based on the findings. For instance, most of the parents argued and agreed that there were more advantages of bilingualism as compared to its disadvantages. For instance, the children feel uncomfortable learning two or more second languages at the same time. In the present case, the children learn two languages from their parents and also try to understand/learn another language of their grandparents. However, there could be seen hesitation for the child learning two bilingualism setups at the same time. For instance, in the first family in Germany, the girl's mother could speak English as well as German well, yet her grandparents couldn't speak both languages, hence, they speak another language, Urdu. The research could not find a positive list of benefits as the child was very younger. But it doesn't mean that everywhere and in every situation, the result would be seen, as it has been observed in the remaining families where it seems that to be bilingual or multilingual could be beneficial because parents of the kids, every time, wished and intended their child might learn the languages more than one. For instance, a benefit for the present child would be positive when she goes to a job which requires both languages German and English. But in the case of Germany, this could be far from the reach of the child as English is rarely spoken or focused in the market. In the same way, other families under observation possess the same idea that their generations would be better able to get highly paid jobs if they get success in making their children at least bilinguals.

Moreover, bilingual speakers could be considered more open-minded as they learn the values of more than one culture through language. (see Raguenaud, 2009, pp. 114-115 for more details). The interviewed questions were summarized, and the same result was found that parents were in favor of bilingualism and they wanted their children to get benefit from this dual ability. However, this is now the responsibility of language therapists and experts to guide and support parents and teachers so that advantages can be enhanced.

\section{Conclusion}

The main objective of the research is to investigate the pros and cons of bilingualism specifically in language learning and development of children in their early age in relation to this the role of language therapist. This case study explored certain concerns of parents while raising their children as bilinguals. The present research could find more advantages and disadvantages if it was conducted at a wider level. For instance, there could be included more than 7 children for clearer results. Although, the study was not very difficult, yet the timeframe was limited. If the researchers could find more time, the area of the study could also be enhanced as many advantages and disadvantages more than mentioned. Whereas advantageous are concerned it may be concluded in this limited study that advantages are more in number and the learners are ever in advantageous position being more skilled in communication and learning process. Furthermore, they feel satisfied and elevated because bilingualism or multilingualism brings confidence in them to face the issues more and more. This can be proved by the example of modern technology where the learned, especially bilingual can understand the depth and functions of the devices or gadgets, on the other hand, monolingual can't perform the action of operating such technical devices, in this way his performance would always be below.

Moreover, the interviews were also limited in number to support the in-depth analysis. The present research could be considered a pilot study and would be enhanced in the future. But this observation that language therapists can play a significant role to take maximum benefit out of this ability differs according to situations. The research topic could be studied further by, for example, focusing more on the differences between bilingual children who speak two majority languages and children who articulate either two minority languages or a minority language and a majority language. It was noticed, already in the study, that there seem to be some differences in the children's attitudes towards bilingualism and which methods the parents use when training their children as bilinguals.

Hence, the researchers come to conclude that in the light of the theorists' experiences, their theories, and the present case study, it proves whether there exists a majority language or minority language, parents urge to make their child a bilingual and they feel pleasure and satisfaction regarding his bright future and high status in spite of facing a lot of difficulties in this process, and it doesn't matter whether they have to get the services of the trainer to get their goal. 


\section{References}

Aazam, F., Baig, F. Z., Baig, T., Khaliq, S., Azam, A., Shamshad, S., \& Aslam, M. Z. (2019). A Critical Discourse Analysis of 'Fire and Fury: Inside the Trump White House' by Michael Wolff. International Journal of English Linguistics, 9(4), 192-199. https://doi.org/10.5539/ijel.v9n4p192

Baker, C. (2000). A Parents' and Teachers' Guide to Bilingualism. Multilingual Matters: Clevedon, England; Buffalo, NY.

Barron-Hauwaert, S. (2011). Bilingual siblings: language use in families. Multilingual Matters: Bristol, Buffalo. https://doi.org/10.21832/9781847693280

Ben-Zeev, S. (1977). The influence of bilingualism on cognitive strategy and cognitive development. Child Development, 48(3), 1009-1018. https://doi.org/10.2307/1128353

Bialystok, E., Craik, F. I. M., Klein, R., \& Viswanathan, M. (2004). Bilingualism, Aging, and Cognitive Control: Evidence from the Simon Task. Psychology and Aging, 19(2), 290-303. https://doi.org/10.1037/0882-7974.19.2.290 PMid:15222822

Blom, E., Boerma, T., Bosma, E., Cornips, L., \& Everaert, E. (2017). Cognitive Advantages of Bilingual Children in Different Sociolinguistic Contexts. Frontiers in Psychology, 8, 552. https://doi.org/10.3389/fpsyg.2017.00552 PMid:28484403

Brice, A., \& Brice, R. (eds.) (2009). Language development: Monolingual and bilingual acquisition. Columbus, $\mathrm{OH}$ : Pearson Education.

Byers-Heinlein, K., \& Lew-Williams, C. (2013). Bilingualism in the Early Years: What the Science Says. Learning Landscapes, 7(1), 95-112. https://doi.org/10.36510/learnland.v7i1.632

Callan, E. (2008). Critical Review: Does bilingualism slow language development in children? Retrieved November 25, 2019, from https://pdfs.semanticscholar.org/c68f/9e926bcf400afd4a899d0ebc08ce87920015.pdf

Cortina, R., Makar, C., \& Mount-Cors, M. F. (2015). Dual language as a social movement: Putting languages on a level playing field. Current Issues in Comparative Education, 17(1), 5-16.

Costa, A., Hernandez, M., \& Sebastian-Gales, N. (2008). Bilingualism aids conflict resolution: Evidence from the ANT task. Cognition, 106, 59-86. https://doi.org/10.1016/j.cognition.2006.12.013 PMid:17275801

Cummins, J. (2000). Language, power, and pedagogy. Bilingual children in the crossfire. Clevedon, England: Multilingual Matters. https://doi.org/10.21832/9781853596773

Fernald, A. (2006). Childhood Bilingualism: Research on infancy through school age. Multilingual Matters: Clevedon.

Fierro-Cobas, V., \& Chan, E. (2001). Language Development in Bilingual Children: A Primer for Pediatricians. Contemporary Pediatrics, 18(7), 79-98.

FKA. (n.d.). Retrieved September 10, 2019, from http://fka.org.au/

Fuller, J. (2008). Language Choice as a Means of Shaping Identity. Journal of Linguistic Anthropology, 17(1), 105-129. https://doi.org/10.1525/jlin.2007.17.1.105

Gold, B. T., Kim, C., Johnson, N. F., Kryscio, R. J., \& Smith, C. D. (2013). Lifelong Bilingualism Maintains Neural Efficiency for Cognitive Control in Aging. Journal of Neuroscience, 33(2), 387-396. https://doi.org/10.1523/JNEUROSCI.3837-12.2013

Goundar, P. R., \& Kaur, M. (2016). Multilingualism, the Linguistic Landscape of Fiji. International Journal of Humanities and Cultural Studies, 2(4), 625-632.

Haman, E., Wodniecka, Z., Marecka, M., Szewczyk, J., Białecka-Pikul, M., Otwinowska, A., ... Foryś-Nogala, M. (2017). How Does L1 and L2 Exposure Impact L1 Performance in Bilingual Children? Evidence from Polish-English Migrants to the United Kingdom. Frontiers in Psychology, 8, 1444. https://doi.org/10.3389/fpsyg.2017.01444

Hamel, J., Dufour, S., \& Fortin, D. (1993). Case study methods. SAGE: Newbury Park, CA. https://doi.org/10.4135/9781412983587

Hamers, J. F., \& Blanc, M. (2000). Bilinguality and Bilingualism. Cambridge: Cambridge University Press. https://doi.org/10.1017/CBO9780511605796 
Kandolf, C. (1995). Myths about Bilingualism. Retrieved September 30, 2019, from http://www.nethelp.no/cindy/myth.html

Lowry, L. (2015). Bilingualism in Young Children: Separating Fact from Fiction. Hanen Early Language Program. The Hanen Centre. Retrieved November 25, 2019, from http://www.hanen.org/SiteAssets/Helpful-Info/Articles/Bilingualism-in-Young-Children-PF.aspx

Marian, V., \& Shook, A. (2012). The cognitive benefits of being bilingual. Cerebrum: The Dana Forum on brain science, 13.

Mohanty, A. K. (1994). Bilingualism in a Multilingual Society: Psychosocial and Pedagogical Implications. Mysore: Central Institute of Indian Languages.

Nelson, J. (n.d.). The Benefits of Being Bilingual: People Think You're a Genius. Retrieved September 30, 2019, from https://www.omniglot.com/language/articles/benefitsofbeingbilingual.htm

Paradis, J., Crago, M., Genesee, F., \& Rice, M. (2003). French-English bilingual children with SLI: How do they compare with their monolingual peers? Journal of Speech-Language and Hearing Research, 46(1), 113 127. https://doi.org/10.1044/1092-4388(2003/009)

Potgieter, A. P. (2014). The Role of Input in the Early Trilingual Acquisition of English, Afrikaans, and Isixhosa. Ph.D. Thesis, Stellenbosch University. Retrieved September 30, 2019, from https://pdfs.semanticscholar.org/c779/8e49b3d2d4656224c3df2696c2e473419ee6.pdf

Raguenaud, V. (2009). Bilingual by choice: Raising kids in two (or more!) languages. Nicholas Brealey Pub: Boston.

Sampath, K. K. (2005). Effect of Bilingualism on Intelligence. In C. James, T. M. Kara, R. Kellie \& M. Jeff (Eds.), Proceedings of the 4th International Symposium on Bilingualism (pp. 2048-2056). Somerville, MA: Cascadilla Press.

Scarino, A., \& Liddicoat, A. J. (2009). Teaching and Learning Languages: A Guide. Australian Government: Department of Education, Employment and Workplace Relations.

Statistics Canada. (2007). 2006 Census: Immigration, citizenship, language, mobility, and migration. Retrieved from http://www.statcan.gc.ca/daily-quotidien/071204/dq071204a-eng.htm

Toronto.ca. (2018). Toronto's Racial Diversity. Retrieved from http://www.toronto.ca/toronto_facts/diversity.htm

U.S. Department of Education, National Center for Education Statistics. (n.d.). Retrieved from $\mathrm{http}: / /$ nces.ed.gov/fastfacts/display.asp?id=96

Valian, V. (2015). Bilingualism and cognition. Bilingualism: Language and Cognition, 18(1), 3-24. https://oi.org/10.1017/S1366728914000522

\section{Appendix A}

1) Do you know many bilingual people?

2) Is your child bilingual? If so, which factors motivated you to decide to raise her bilingual?

3) If not, which concerns made you decide not to do so?

4) Which languages do you and your spouse use when talking to your child? Which language/languages do you use when you are spending time together as a family?

5) Have you noticed that being bilingual has affected your child's life somehow?

6) How have you raised your child bilingual? Have you used any certain techniques?

7) What do you think of bilingualism? Do you think it has any advantages or disadvantages?

8) How can a language therapist contribute to overcome the disadvantages of bilingualism and maximize the advantages?

\section{Copyrights}

Copyright for this article is retained by the author, with first publication rights granted to the journal.

This is an open-access article distributed under the terms and conditions of the Creative Commons Attribution license (http://creativecommons.org/licenses/by/4.0/). 